\title{
CARTOGRAFIAS DA MIGRAÇÃO NA LITERATURA QUEBEQUENSE CONTEMPORÂNEA
}

\author{
Maria Bernadette Velloso Porto
}

\begin{abstract}
Os escritores da migração são então novos nômades de nosso mundo fragmentado e estilhaçado com um imaginário da multiplicidade: várias línguas, vários passaportes, idas e vindas, diásporas, exílios mais ou menos temporários, voluntários e involuntários, fixações efêmeras, percursos, itinerários, imaginário da metamorfose em nível dos gêneros, da língua $(. . .)^{1}$
\end{abstract}

Fenômeno socio-cultural de dimensão planetária, as migrações adquirem uma visibilidade crescente nos dias de hoje através do número cada vez mais expressivo de seres deslocados - refugiados, exilados políticos, fugitivos da miséria, de lutas e de guerras - que, impulsionados por muitas razões, deixam sua terra natal para vivenciar, no espaço alheio, as promessas de novos recomeços. A experiência migratória supõe a capacidade de adaptação a condições muitas vezes adversas, o que confere ao homem um traço que o distingue de outros seres vivos: se plantas e animais não sobrevivem fora de seu habitat natural e se aves migrantes obedecem a um itinerário fixo e previsível, o homo migrans tira partido dos riscos da imprevisibilidade e de

\begin{tabular}{|l|l|l|l|l|}
\hline Ilha do Desterro & Florianópolis & $n^{\circ} 40$ & p.085-106 & jan./jun. 2001 \\
\hline
\end{tabular}


estratégias de sobrevivência capazes de assegurar sua continuidade e sua reinvenção para além dos limites de sua pátria (Guerrero, 2000, p. 12).

A história de diferentes povos e civilizações sempre foi marcada por deslocamentos plurais e a própria América, enquanto palco privilegiado de "coletividades novas" (Bouchard, 2000), constitui um lugar exemplar para se repensarem os vínculos entre migrações e reelaborações identitárias. Aos olhos do escritor e ensaísta antilhano Édouard Glissant (1995, p. 13), ao longo de séculos de apropriação e povoamento do continente americano, há que se reconhecer diversas formas de migração que correspondem a modos distintos de inserção nas Américas: a) "migrante fundador" ou "migrante armado", o colonizador para cá se deslocou com seus barcos e suas armas, através de um "nomadismo em flecha", diferente do "nomadismo circular" necessário à sobrevivência de comunidades como a dos arauaques que, antes da descoberta da América, se deslocavam de ilha em ilha no mar das Caraíbas (Glissant, 1990, p. 24); b) movido pelo objetivo de povoar o novo continente, o "migrante familiar" ou doméstico trouxe na sua bagagem seu forno, seus utensílios cotidianos (como as panelas), suas fotos de família; c) finalmente, trazido pela violência do tráfico de escravos que o despojou de seus bens reais e simbólicos, o "migrante nu" teve de apelar para formas criativas de resistência para escapar à ameaça de despersonalização e aniquilamento. Para além das especificidades das migrações detectadas por Glissant nas Américas às quais se acrescenta sempre o movimento de constantes fluxos migratórios - identifica-se, em cada um dos casos, o elo indissolúvel entre movências e mutações.

$\mathrm{Na}$ verdade, a migração não é nunca sem conseqüências, provocando profundas metamorfoses na relação que o ser migrante estabelece com o tempo, com seu cotidiano, com sua história, com o espaço circundante e o espaço ausente e até mesmo com a expressão lingüística (cf. as tensões entre língua materna e idioma estrangeiro). Vivenciadas, muitas vezes, como ferida simbólica afetada por um grau maior ou menor de dilaceramento, as diversas formas do ato de migrar 
não podem ser reduzidas a um denominador comum pois, apesar da existência de fenômenos que parecem se repetir em toda desterritorialização, condições particulares interferem na trajetória dos que se afastam de sua terra natal, determinando modos diferenciados de se viver e de se trabalhar o exílio que pode deixar de ser encarado como experiência traumatizante para se tornar produtivo. De qualquer maneira, não é fácil o processo de integração do imigrante à cultura estrangeira, já que ele não pode saltar de um sistema cultural para outro, como se mudasse simplesmente de um compartimento para outro num trem (Ancelovici, Dupuis-Déri, 1997, p. 205). Da mesma forma, não é possível para o imigrante despir-se de sua identidade como se ela fosse uma roupa que não mais lhe coubesse. Com o passar do tempo, os imigrantes são até capazes de romper, em níveis diversos, com sua terra natal, podendo inclusive descobrir que "seu país se tornou estrangeiro para eles sem que o país estrangeiro tenha se tornado um país para eles" (Palmier, 1988, p. 367). Colocado num impasse entre o "não mais" e o "ainda não", o ser migrante demonstra que a identidade não é dada de uma vez por todas, pois ela se constrói e se transforma ao longo da existência (Maalouf, 1998, p. 33). A prática migrante mostra ainda que "a identidade é aquilo que herdamos de nossos pais, mas também o uso que é feito de tal herança" (Ancelovici, Dupuis-Déri, 1997, p. 135).

Direcionando suas reflexões para seres que carregam em si o peso de pertencimentos que se afrontam violentamente - seres fronteiriços atravessados por linhas de fratura étnicas, religiosas ou outras - o escritor e ensaísta Amin Maalouf - que se define como libanês e francês - crê que os indivíduos são cada vez mais sensíveis à experiência dos migrantes e minoritários. Para ele, hoje, os homens compartilham uma sensibilidade migrante a tal ponto desenvolvida que se pode perguntar: "Não é próprio de nosso tempo ter feito de todos os homens uma espécie de migrantes e minoritários? (Ancelovici, Dupuis-Déri, 1997, p. 171). Para Maalouf, somos todos obrigados a viver num universo que pouco se assemelha a nosso território de origem, todos nós devemos aprender 
outras línguas e temos a impressão de que nossa identidade está ameaçada (Maalouf, 1998, p. 53). Por isso mesmo, numa época em que se evidenciam marcas contraditórias da harmonização e da dissonância, em que os indivíduos compartilham tantas referências, palavras e imagens que circulam em toda parte, sobretudo graças à forca insidiosa da mídia, e à internacionalização da cultura de massa, a mundialização acelerada provoca, em contrapartida, o reforço da afirmação identitária.

Falar em migrações no mundo pós-colonial nos leva a reconhecer a proliferação de fenômenos que embaralham nossas referências habituais: ao lado do processo crescente de misturas de culturas - visto como mestiçagem por alguns (entre outros, Gruzinski, 2001) ou como crioulização por teóricos antilhanos (Glissant, 1990) - identifica-se o recrudescimento da defesa de tradições locais, de nacionalismos, etnicismos e culturalismos. Nesse contexto se sobressai a ambigüidade da consciência contemporânea: ao lado da recusa do heterogêneo, manifesta-se o apelo do híbrido e da impureza em produções culturais de nosso tempo (Nepveu, 1988, p. 210).

Em espaços culturais tornados cada vez mais globalizados e mesclados, onde transitam não só seres hifenizados - isto é, definidos por duplos pertencimentos - mas também indivíduos marcados por pertencimentos plurais, ressaltam-se reações divergentes: paralelamente ao medo da uniformização, irrompe o temor da fragmentação. É o que se privilegia em inúmeras publicações centradas nas experiências migratórias surgidas no pós-colonial, que ilustram a revisão de noções como fronteira, nação, origem, cultura nacional. Obras literárias surgidas em todo mundo representam novas paisagens sociais, novos imaginários que exprimem o esgotamento das chamadas literaturas nacionais e a crise na ordem das filiações identitárias. Como pensa o teórico quebequense Jean Larose, não há identidade moderna sem movimento e estilhaçamento, sendo altamente problemático conceber a identidade, hoje, a partir da idéia de nacionalismo (Ancelovici, Dupuis-Déri, 1997, p. 72).

Nas Américas - e, em particular, no Canadá e nos Estados Unidos - a imigração e o multiculturalismo constituem fatores que afetam as 
certezas identitárias. No que concerne aos Estados Unidos, quem poderia apoiar a identidade americana no modelo dos WASP (White Anglo-Saxon Protestant)? Assim, abrindo-se para acolher imigrantes em seu território, países como os citados introduziram um elemento de abertura e de conflito no seio da identidade nacional. Ao se afastarem da concepção essencializante e monolítica da identidade nacional, muitos autores nômades trouxeram para o centro de debates a releitura do conceito de identidade, pois se a origem pode ser renovada no espaço do Outro e se as memórias pessoais e coletivas são susceptíveis de serem continuamente reinventadas, todo indivíduo - que traz sempre consigo as marcas de paisagens afetivas primordiais - tem também o direito de fazer novas escolhas, de eleger outros lugares para se reterritorializar, assegurando o seu inacabamento identitário.

Em se tratando do Quebec, o surgimento relativamente recente de novas ondas migratórias oriundas, em parte, do Terceiro Mundo (do Haiti, do Maghreb, do Oriente Médio e do Extremo Oriente), trouxe novos dados para a configuração da cartografia identitária coletiva, acarretando uma outra leitura da identidade nacional. Assim, ao lado de imigrantes de origem européia, representantes das Antilhas, Ásia e África se instalaram, ao longo dos últimos vinte ou trinta anos, em solo quebequense, onde também participam da produção cultural que se enriqueceu com a multiplicidade de memórias e de referências identitárias.

Cabe lembrar aqui a homogeneidade atribuída pelas elites do século XIX à comunidade francófona do Canadá, que se fundamentava na ocultação de clivagens e diversidades existentes no seio desse grupo minoritário. Assim, até os anos 60, era difundida a crença da monoidentidade minoritária do Canadá, que se mantinha graças à defesa da língua francesa e da religião católica. Segundo o sociólogo Gérard Bouchard, no pensamento de tais letrados, a sociedade canadense francesa era vista como organicamente integrada, o que não dava conta dos conflitos característicos de uma sociedade em vias de industrialização (Bouchard, 2000, p. 24). 
Com a vinda significativa de novos fluxos de imigrantes não europeus, a heterogeneidade existente no interior da cultura quebequense assume uma visibilidade significativa. Se até recentemente muitas obras literárias quebequenses privilegiavam a questão nacional através da representação ficcional das tensas relações entre francófonos e anglófonos, nos anos 80, com o ingresso e o reconhecimento por parte da crítica, de autores migrantes no campo literário quebequense, coloca-se de outra forma a presença do Outro, disseminado na pluralidade de origens e bagagens culturais. Para ilustrar a mudança na maneira de se encarar o Outro na produção migrante do Quebec, pode ser aqui lembrada a apropriação feita por Marco Micone (de origem italiana) dos célebres versos que aparecem no fim do poema "Speak White" de Michèle Lalonde ("Sabemos que não estamos sós"). No poema de Lalonde, depreende-se a inquietação dos quebequenses diante da presença ameaçadora do colonizador de língua inglesa, ao passo que, retomado por Micone em "Speak What" o mesmo enunciado sugere a possibilidade da partilha e das trocas enriquecedoras com representantes de outros grupos culturais, "cem povos vindos de longe" para dividir com os quebequenses "seus sonhos e seus invernos", e que se propõem a falar francês com seu "verbo bastardo" e seus "sotaques rachados" para lhes dizer que eles não estão sós. Daí decorre ainda o aspecto inacabado da identidade quebequense que deixa de ser definida apenas pelo passado para abrir-se para a possibilidade de transformações em aberto (Kwaterko, 1992, p. 2).

Ao apostar na mobilidade e no descentramento como categorias estéticas e ao se apresentar como "uma prática concreta de desterritorialização" (Nepveu, 1989, p. 21), a chamada literatura migrante do Quebec contemporâneo constitui um espaço privilegiado para se refletir sobre o lugar do heterogêneo nas produções culturais da pós-modernidade e do pós-colonial. Embaralhando múltiplos pontos de referência e misturando as categorias do próximo e do distante, do familiar e do estrangeiro, do semelhante e do diferente (Nepveu, 1988, p. 199-200), textos migrantes nascidos no Quebec assumem um caráter 
polifônico, associado ao roçar de diversas vozes, sotaques e lembranças. Situados numa encruzilhada de línguas e memórias culturais, tais textos revestem-se de um aspecto híbrido, como se depreende dos versos do poema "Babel" de Antonio D'Alfonso, que, propositalmente, não traduziremos:

\author{
Nativo di Montreal \\ élévé comnme Québécois \\ forced to learn the tongue of power \\ viví en Mexico como alternativa \\ figlio del sole e della campagna \\ par les francs-parleurs aimé \\ finding thousands like me suffering \\ me casé y divorcié en tierra fría \\ nipote di Guglionesi \\ parlant politique malgré moi \\ steeled in the school of Old Aquinas \\ queriendo luchar con mis amigos latinos \\ Dio where shall I be demain \\ (trop vif) que puedo saber yo \\ spero che la terra be mine.
}

Na qualidade de texto híbrido, o poema acima parece interrogar os imaginários do pertencimento, apontando ainda para o que Sherry Simon considera como um processo de tradução inacabada (Robin, 2000, p. 35) onde se destacam efeitos de desterritorialização graças à incorporação de idiomas estrangeiros. $\mathrm{Na}$ verdade, todo imigrante vivencia o exercício da tradução vista como forma de migração imóvel aos olhos do escritor haitiano Anthony Phelps (Gravili, 2000, p. 88), ou como exemplo da poética da Relação aos olhos de Glissant (1995, p. 36), que se oporia à idéia de limitação do ser. A referência à tradução se faz aqui necessária para se refletir sobre o que se passa na contemporaneidade, onde Salman Rusdhie (Imaginary Homelands) 
reconhece o aparecimento de um número maior de homens traduzidos, frutos do imbricamento de várias histórias, línguas e culturas.

É preciso lembrar uma distinção adotada por muitos autores quebequenses vinculados, pela sua teoria ou pela sua prática, à produção migrante: trata-se da diferença entre os termos imigrante e migrante para designar tal literatura. O primeiro se refere à experiência do exílio, às dificuldades de adaptação ao novo país. Já o segundo, preferencialmente escolhido para definir obras situadas em entrelugares marcados pelas diferenças culturais e pela travessia de línguas, corresponde a um exercício estético, sugerindo "o vaivém entre dois lugares, o conceito de re(des)territorialização e uma certa deriva" (LEQUIN, 1992, p. 31). Assim, não se trata apenas de representar, em nível ficcional, histórias de personagens exilados e deslocados, mas também de explorar, na própria escrita, o nomadismo como prática produtiva. Muitas vezes, através da passagem de uma língua a outra, de um imaginário a outro, tira-se partido da movência textual, o que confirma o prestígio da atividade tradutória nos textos migrantes. É o que se destaca em outro texto de Antonio D'Alfonso: “Quando escrevo, tenho na cabeça a memória de uma língua e exprimo essa memória em outra língua. Um casamento de memórias" (D'Alfonso, 1987, p. 126-127).

Recorrendo aos recursos da prática do "trans" e do "entre-dois" (Sibony, 1991), a produção migrante quebequense remete freqüentemente ao fenômeno da "transcultura", termo criado por Fernando Ortiz para explicar a realidade cubana. Palavra "que contém uma parte de dor, a inevitável dor das mutações" na ótica de uma personagem imigrante do romance que tem o título significativo de Nous avons tous découvert l'Amérique (Noël, 1992, p. 243), a transcultura supõe um processo inacabado de metamorfoses nascido do confronto criativo entre culturas diferentes. Assim é

sempre um processo no qual algo é dado em troca do que se recebe: as duas partes da equação se encontram modificadas por sua causa. Daí emerge uma realidade nova que não é um 
mosaico de caracteres, mas um fenômeno novo, original e independente. (Lamore, 1992, p. 47)

No âmbito da produção literária migrante do Quebec, devem ser ressaltadas referências identitárias que, ao lado da quebequense, participam do jogo transcultural, contribuindo para a via de mão dupla entre mundos diversos que se irrigam reciprocamente. Vozes vindas de muitos cantos do universo utilizam-se do francês como língua da criatividade, mostrando que a mesma se tornou o veículo de expressão de diferentes heterogeneidades. Imigrantes deixam de ser "gens $d u$ silence" (título de uma peça de teatro de Marco Micone) para clamar sua diferença em francês, como o brasileiro Sergio Kokis, o iraquiano Naïm Kattan e as egípcias Anne-Marie Alonzo, Nadine Ltaif e Mona Latif-Ghattas, entre outros, que conquistaram um lugar de destaque no seio da literatura quebequense. Detentores de prêmios e reconhecidos pela crítica, ganharam a legitimação no interior do campo literário onde se inserem, o que provoca certo mal estar por parte de alguns quebequenses que os vêem como "estranhos no ninho", já que eles não têm na sua bagagem identitária as lembranças de Jacques Cartier, do "coureur de bois", da derrota nas Plaines d'Abraham.

Duas comunidades de migrantes em particular podem ser aqui destacadas: a dos haitianos e dos italianos (e seus descendentes). Entre 1968 e 1983, o Haiti ocupou o primeiro lugar entre os países de imigração no Quebec, não só devido à repressão de Duvalier, mas também à política de imigração canadense. Vinculados ao que Maximilien Laroche considera o "duplo palco da representação" (1991), autores haitianos instalados no Quebec exploram a não coincidência da memória cultural haitiana com a terra que os acolhe. É o que se verifica no romance Passages de Émile Ollivier (1991), texto da errância que exprime a dificuldade de ser haitiano, não só em espaços da diáspora (Montreal, Miami), mas ainda no próprio Haiti. Colocando-se, no conjunto de sua obra, à escuta da memória estilhaçada e reconstituindo os fios da história esgarçada do país perdido, Ollivier não deixa de ser marcado pelo contexto quebequense (Brière, 1996, p, 62). 
Quanto aos autores de origem italiana, é significativa sua presença em várias áreas culturais, como a produção literária e crítica, a tradução, a edição e o jornalismo. É o caso, por exemplo, de Fulvio Caccia, fundador da revista Vice Versa e organizador dos livros Quêtes (em parceria com Antonio D'Alfonso) e Sous le signe du Phénix, centrados em autores ítalo-quebequenses que aí refletem sobre o devir minoritário e sua situação de indivíduos hifenizados. É também Fulvio Caccia, segundo Pierre Nepveu (1989, p. 20), quem atribuiu ao conceito de transcultura uma base quebequense, ao apontar o inacabamento da francidade entre os quebequenses, o que tornaria viável um outro devir no âmbito dessa cultura. E por que não evocar ainda o papel do professor, dramaturgo, escritor e ensaísta Marco Micone que, ao tratar da sua cultura de origem, fala também da realidade quebequense?

Associada a contextos culturais diversos e a condições de produção variadas, a literatura migrante do Quebec remete, de fato, a distintas situações, não devendo ser considerada sob a rubrica da homogeneidade. Trata-se de autores oriundos de países muito díspares dos quais se afastaram por motivos diferentes e que experimentam, de muitos modos, a vivência do exílio. Exílio lingüístico, cultural e geográfico conhecido de perto por escritores que se deslocaram de seus países ou ainda, exílio vivido por procuração, herdado pelos descendentes de imigrantes que receberam dos pais, como bagagem identitária, as lembranças de um país imaginário, perdido e impossível de ser recuperado. Além disso, nem todos os autores migrantes do Quebec conhecem na pele os apelos de um duplo pertencimento explicitado sob a ambivalência do "entre-dois", visto como impasse e / ou como convite para se ir além. É o caso do tunisiano Hédi Bouraoui que afirma ter saído da dualidade estéril que afeta os escritores magrebinos - a binaridade infernal das tensões entre colonizador e colonizado - graças à vivência da migração. Valendo-se de sua experiência transcultural, sente-se herdeiro de três espaços: a Tunísia, seu país natal que lhe legou valores ancestrais da cultura africana, a França, lugar onde viveu e estudou na adolescência e o Canadá, seu 
país de adoção. Como se ilustrasse idéias explicitadas por Amin Maalouf no seu ensaio Les identités meurtrières sobre a construção identitária a partir de múltiplos pertencimentos, Hédi Bouraoui declara que, em seus trânsitos culturais, não se sentiu nunca exilado, vitimizado ou alienado por nenhum dos componentes de sua identidade (Bélanger, 2000, p. 14).

No interior da literatura migrante produzida no Quebec destacase um outro recorte possível para análise: os textos de autoras nômades que interrogam os vínculos entre escrita, exílio e migração. Segundo Lucie Lequin, especialista no assunto, ao se tratar de tal produção, devese evitar o risco da rubrica "escrita feminina" que sugeriu, ao longo de histórias literárias, a inferiorização de certas autoras lidas sob essa ótica, ao contrário de grandes escritoras - como Gabrielle Roy e Anne Hébert - estudadas em pé de igualdade com obras de autoria masculina (Hanciau; Campello \& Santos, 2001, p. 267). Reconhecendo que textos migrantes no feminino tiram sua força do movimento, das incertezas e do convívio das pluralidades, Lequin reconhece que eles podem modificar o tecido literário quebequense.

De fato, longe de se enclausurar num compartimento exótico ou numa espécie de gueto - risco que não deixa de correr, segundo teóricos e escritores - a literatura migrante se insere no campo literário quebequense, incluindo-se no seu devir, abrindo-se para o diálogo com autores consagrados da tradição literária do Quebec. Isso é possível porque o interesse pelo heterogêneo e a presença do exílio (físico ou fictício), da falta, do país ausente ou inacabado já estavam presentes no imaginário coletivo desde os anos 60 no Quebec (Nepveu, 1988, p. 200201). Dessa forma, vista por Nepveu (1998) como "literatura pósquebequense" - pelo fato de ultrapassar a questão nacional - a literatura migrante explora aspectos que já faziam parte do horizonte quebequense. Por sua vez, obras de autores não migrantes inspiramse na perspectiva nômade: é o caso, por exemplo, do conto "Pur polyester" de Lori Saint-Martin, cuja narradora, de origem hispânica, ao se definir como "puro poliester", contesta o mito do "Québécois 
pure laine" (quebequense pura lã) associado ao ideal de pureza e homogeneidade étnica (Porto, 2000).

Um dos eixos privilegiados em obras migrantes - presente no conto de Lori Saint-Martin e no romance La Québécoite (1993a) de Régine Robin, referência obrigatória desse tipo de produção - referese à dicotomia ser / tornar-se quebequense. Ao dizer que seus pais imigrantes espanhóis (cf. Porto, 2000, p. 41: "Só estou em exílio por causa de mamãe-papai. Não sou de lugar nenhum, apenas, talvez, um pouco, já daqui") quiseram lhe dar a chave de um país para eles fechado para sempre, a narradora acrescenta:

Estou com eles, estou completamente sozinha, estou também com as pessoas daqui, de meu não-totalmente-mas-quasepaís. Entre-dois, na brecha, tornando-me, talvez-mas isso é possivel? - quebequense. (Porto, 2000, p. 47)

Tal questionamento, central também em passagens do romance La Québécoite, onde aparece como hipótese inquietante expressa pelo emprego do futuro do pretérito, se insinua em polêmicas criadas em torno da inclusão de autores de origens plurais no âmbito da literatura quebequense. Em outras palavras, pergunta-se: o que assegura a alguém o direito de ser visto como quebequense? A nacionalidade pode ser encarada pelos laços de sangue ou por uma escolha? Ou ainda, retomando considerações de Glissant sobre questões identitárias na contemporaneidade, pode-se indagar: como é possível ser o que se é sem se fechar ao outro, e como é possível abrir-se ao outro sem se perder a si mesmo? (Glissant, 1995, p. 20).

Permitindo-nos uma breve digressão em direção ao Brasil, cabe lembrar que aspectos privilegiados na literatura migrante quebequense nos remetem às negociações identitárias estabelecidas, ao longo da história, entre imigrantes e brasileiros. Aos olhos de um estudioso do assunto, Jeffrey Lesser (2001), o Brasil permanece um país onde a etnicidade hifenizada é predominante, embora não reconhecida. Isso 
se dá, em parte, em função do discurso das elites que pregavam a idéia de uma identidade nacional europeizada e homogênea (2001, p. 20). De fato, durante muito tempo, orientadas pela perspectiva da eugenia, políticas de imigração incentivavam o ingresso de imigrantes "desejáveis" que pudessem "embranquecer" o país, pois pensava-se que, à medida que os colonos se tornassem brasileiros, o Brasil se tornaria europeu (2001, p. 26). Logo, a manipulação política fez da imigração um fator decisivo na construção da identidade nacional. Mais tarde, com mudanças de ordem social e econômica, foi necessário acolher imigrantes não europeus, como os chineses, o que representou "uma solução para um duplo problema: uma classe servil embora não escrava poderia ser criada para desafricanizar o Brasil" (Lesser, 2001, p. 38). Não foi por acaso que, como lembra Lesser, a novela "Os imigrantes" da Rede Bandeirante, foi anunciada a partir do reconhecimento da identidade múltipla brasileira: "Portugueses, japoneses, espanhóis, italianos, árabes. Não perca a mais brasileira das telenovelas".

Ao discorrer sobre um prédio situado no Bom Retiro, tradicional bairro de imigrantes de São Paulo, Lesser aí identifica a coexistência das marcas de diferentes culturas em cada lojinha, em cada lanchonete e em cada botequim onde se poderia reconhecer os sinais de uma babelização feliz. Interessam-nos, em particular, as referências feitas por Lesser às mestiçagens e ao entrecruzamento transcultural, como o do exemplo de uma dupla sertaneja chamada Nissei \& Sansei, o que confirma que as migrações, as mutações e as trocas culturais caminham juntas.

Do ponto de vista literário, textos brasileiros marcados por diferentes componentes autobiográficos e ficcionais - e é bom lembrar que a memória é também invenção - tiram partido da situação identitária de autores marcados pela ambivalência do entre-dois. Autores como Salim Miguel (Nur), Milton Hatoum (Relato de um certo Oriente, Dois irmãos), Samuel Rawet (Contos do imigrante), Lya Luft (A asa esquerda do anjo) refletem sobre o processo nem sempre fácil de integração ao país novo e às tensões decorrentes da oposição entre ser e tornar-se. 
Embora pudéssemos recorrer a exemplos reveladores de tais autores, entre outros, preferimos evocar aqui outra passagem do livro de Lesser, quando ele afirma que, segundo um dito popular brasileiro, quando alguém chega do Oriente Médio, ele é turco. Depois de conseguir seu primeiro emprego fixo, ele se torna sírio. Ao se tornar proprietário de uma loja ou de uma fábrica, ele é transformado em libanês. E aí Lesser se pergunta: mas quando é que ele se torna brasileiro? Da mesma forma, obras migrantes produzidas no Quebec se interrogam sem cessar se é possível, para um imigrante, tornar-se, de fato, quebequense.

Longe de serem esgotadas e de conhecerem uma única resposta, questões desse gênero circulam em vários textos migrantes onde são tratadas com maior ou menor dose de otimismo. Ao refletir em uma conferência (1996) sobre as tensas relações entre autores migrantes e quebequenses de "souche", a escritora Monique LaRue mostrou que, para além das especificidades e divergências, tais escritores não deveriam se sentir tão afastados, já que no imaginário quebequense duas figuras míticas, o geômetra e o navegante, sempre estiveram presentes. Correspondendo, de perto, aos dois modelos de narrador analisados por Walter Benjamin, tais figuras devem ser vistas, segundo LaRue, como complementares. Ao primeiro, orientado pela paixão da medida, do sedentarismo e das fronteiras, coube a exploração do território no início da colonização. Quanto ao navegante, impulsionado pela movência que conferia outra dimensão a seu corpo, rompeu limites, largou o passado que levava na bagagem de sua memória. Ao considerar que cada um deles tinha necessidade do trabalho do outro (o navegante não poderia dispensar os gestos do geômetra pois um mundo sem eles seria destituído de marcas e não se poderia esperar que os navegantes se fixassem em cadastros (Larue, 1996, p. 26), LaRue aposta numa identidade quebequense que supõe apropriações e desapropriações, enraizamentos e desenraizamentos, num jogo contínuo entre o ser e o vir a ser.

Também na obra teórica e ficcional de Régine Robin, um dos maiores nomes da identidade em trânsito na literatura do Quebec, é 
explorado o prestígio do devir. Desconfiando da identidade fundamentada no "être", Robin investe nas possibilidades dos "étants" que supõem experimentações identitárias, o fluxo do tornar-se, próprio da figura mítica de Proteu. Um dos deuses secundários do mar na Odisséia, Proteu se reveste do poder de transformação das águas do mar que, durante as tempestades, se assemelham às imagens do cavalo, do porco, do leão, do carneiro. Graças à sua capacidade de se transformar - que se confunde com os movimentos dos "étants" - Proteu catacterizaria, segundo Robin, seres da contemporaneidade, camaleônicos e caleidoscópicos, em perpétua metamorfose, que só existem na disseminação e na fragmentação. Reinventado, hoje, Proteu adquire traços da identidade pós-moderna (entre outros, a desconstrução do eu e a ausência de referências estáveis). Associando a evocação de Proteu aos recursos da Internet, Robin (1996) tira partido das "identidades à la carte", criando pertencimentos fictícios, embaralhando dados biográficos e ficcionais, inscrevendo a estranheza de sua condição judia, engendrando identidades múltiplas, transversais, intercambiáveis ao infinito. Ao se valer das estratégias de Proteu - que talvez correspondam ao desejo de todo escritor que gostaria de estar em toda parte (Robin, 1997, p. 16) - Robin pula de um nome para outro, num jogo identitário marcado pela impossibilidade de um acabamento.

No ir e vir vivenciado entre duas ou mais culturas e memórias, conforme já foi dito, a questão lingüística ocupa uma posição de destaque, pelo fato de que os seres migrantes vivenciam, sob esse aspecto, perdas, impasses e impossibilidades que evidenciam a realização ou não do luto da origem. Situando-se no "inter-dizer", intervalo de travessias plurais de línguas e referências identitárias, a literatura migrante quebequense permite a leitura do exílio enquanto problema que afeta o exercício diário da língua materna, o que supõe resistências, comprometimentos, tentativas de comunicabilidade e o irredutível que se manifesta na passagem de um idioma (ou de uma cultura) a outro/a. 
Inspirado pela contribuição da psicanálise, Jacques Hassoun (1993) interessa-se pelas relações que o sujeito estabelece com a língua materna e, em especial, quando está em jogo a multiplicidade de línguas e culturas que coexistem numa civilização onde se opõem cultura dominante e cultura dominada, língua privilegiada e língua deserdada (1993, p. 45). Para Hassoun, no interior de tal problemática, pode-se perguntar: o que a língua materna significa para populações aculturadas e como se coloca esse problema para os que nascem, vivem e morrem em países de cultura homogênea (diríamos, pretensamente homogênea)? E ainda, que marcas de misturas de línguas ficam registradas no inconsciente? Ao levantar a situação hipotética de um indivíduo que se encontra na confluência de duas ou três línguas, sendo que, pelo menos uma delas - tão querida como as outras - carrega sinais da cultura dominante ou humilhada / humilhante, Hassoun ressalta os efeitos destruidores na história singular do mesmo sujeito, que só podem se manifestar em termos de sofrimento.

Assim, o escritor migrante se depara freqüentemente com o problema doloroso da escolha da língua de criação, o que acarreta conseqüências significativas. Impossibilitado, muitas vezes, de escrever no seu idioma de origem, aprende que o tornar-se estrangeiro está associado a uma privação que coincide com a descoberta de outros referenciais identitários e lingüísticos. Dessa maneira, a vivência da extraterritorialidade e a peregrinação em território não familiar são detectadas nos planos geográfico, cultural e lingüístico. (Harel, 1992, p. 373).

Ao se interrogar sobre a vivência do exílio a partir de sua própria bagagem pessoal e analítica e de entrevistas feitas junto a imigrantes, Julia Kristeva (1992) se pergunta se é possível fazer o luto da língua materna. Apesar de ter identificado, na sua prática de psicanalista, problemas identitários em pacientes exilados que manifestaram distúrbios de memória referentes a seu próprio idioma, Kristeva acredita que não haveria nunca o esquecimento total e definitivo da língua de origem que não se cadaverizaria nunca, podendo, inclusive, em circunstâncias especiais, ser transposta ou reativada de outro modo, no 
idioma do país de adoção. Discorrendo sobre a sua própria vivência, Kristeva diz que, ao escrever livros de semiologia, as lembranças de seu idioma materno ou de seu passado inconsciente não interferiam pelo menos explicitamente - no seu processo de escrita. Mais tarde, ao desenvolver sua prática analítica, reconciliou-se com a língua materna, o que lhe permitiu "traduzir em francês inscrições pulsionais e passionais" acumuladas durante a infância. E quando algumas palavras apareciam por meio de um sonho ou de uma lembrança na língua de origem, ela tentava recolher as sonoridades do búlgaro e encontrar suas ressonâncias em francês (Kristeva, 1992, p. 31).

Baseando-se no seu itinerário pessoal marcado por desterritorializações e reterritorializações graças às quais se vê como "uma pequena América, um pluralismo etnocultural" (Robin, 1994, p. 218), a escritora migrante Régine Robin muito tem contribuído para as reflexões em torno das configurações identitárias na contemporaneidade e, em particular, da escrita de autores nômades. Ao afirmar a necessidade do luto da origem - e da língua materna como condição capaz de assegurar o processo criativo, Régine Robin parece adotar uma postura distinta da de Julia Kristeva a que aludimos. Todavia, apesar de assumirem posições diversas, aparentemente, ambas coincidem no que se refere ao modo de se encarar a origem: se, para Kristeva, deve-se escapar do peso da origem (Kristeva, 1992, p. 32), por meio das possibilidades de escolha da língua de expressão, para Robin, todo escritor - migrante ou não - deve realizar o luto da origem e da língua materna. Isto supõe o ato de "desaprender" sua língua, de deixar repercutir em si mesmo ecos de línguas faladas ou esquecidas, de se deixar penetrar por uma língua desconhecida (Robin, 1993, p. 166), pois para ela o escritor é

aquele que, sem o saber, na maior parte do tempo, faz, graças ao seu trabalho de escrita, o luto da origem, isto é, o luto da língua materna ou, mais exatamente, da crença segundo a qual existe língua materna. O escritor está sempre em 
confronto com o plural, com vozes, línguas, níveis, registros de língua, o heterogêneo, o desvio, o descentramento, mesmo quando ele só escreve naquela que, no plano sociológico, é considerada como uma língua. (Robin, 1993, p. 13)

Ao sugerir que, mesmo escrevendo em sua própria língua materna - como é seu caso - todo escritor tira partido de uma língua desconhecida e da sensação de inquietante estranheza, Robin considera a exploração do descentramento e da condição de estrangeiro para além dos limites da literatura migrante. Ou, em outras palavras, sugere que questões privilegiadas no âmbito dessa produção literária dizem respeito ao ato da escrita em geral.

Caberia lembrar aqui o papel do estrangeiro na relativização das certezas: enquanto figura da alteridade ou da alteração (Harel, 1992, p. 23), ele se questiona sobre o país onde se instala, a partir de um olhar novo e crítico. Não é, pois, gratuito o paralelismo detectado por Robin que, em outro ensaio (1989, p. 13), nos remete à aproximação feita pelo escritor Jacques Godbout (Quebec) entre escrever imigrar. em ambos os casos, trata-se de fazer escolhas, de se recusar a se deixar levar por idéias recebidas. Uma vez que toda escrita pode ser vista como uma atividade de estrangeiro, a literatura - migrante ou não - "é precisamente, o que desfaz as identidades e que desconstrói, corrói as certezas identitárias, compromete o familiarismo tranqüilizador no qual é tão fácil se fechar" (Robin, 1994, p. 231).

\section{Note}

1. Régine Robin

\section{Referências Bibliográficas}

Ancelovici, Marcos and Francis Dupuis-Déri. L'archipel identitaire. Recueil d'entretiens sur l'identité culturelle. Montréal: Boréal, 1997. 
Bélanger, Louis (org.) Métamorphoses et avatars littéraires dans la francophonie canadienne. Montréal: Interlignes, 2000.

Berrouët-Oriol, Robert and Robert Fournier. "L'émergence des écritures migrantes et métisses au Québec". In: Quebec Studies, n 14. Focus on Cultural Pluralism in

Quebec. The American Council for Quebec Studies, 1992. 7-22

Bouchard, Gérard. "Littérature et culture nationale du Québec: le clivage culture savante / culture populaire". In: Porto, Maria Bernadette (org.). Fronteiras, passagens, paisagens na literatura canadense. Niterói: EDUFF/ABECAN, 2000. $15-35$

Brière, Éloise. "Mère solituded'Émile Ollivier: apport migratoire à la société québécoise". In: Canada in the Americas. Canada dans les Amériques. International Journal of Canadian Studies. Revue Internationale d'Études Canadiennes. Ottawa: Carleton University Press, printemps 1996. 61-70

Caccia, Fulvio. Sous le signe du Phénix: entretiens avec quinze créateurs italo-québécois. Montréal: Guernica, 1980.

D’Alfonso, Antonio. L'autre rivage. Montréal: VLB, 1987.

Glissant, Édouard. Introduction à une Poétique du Divers. Paris: Gallimard, 1995. . Poétique de la Relation. Paris: Gallimard, 1990.

Gruzinski, Serge. O pensamento mestiço. São Paulo: Companhia das Letras, 2001.

Guerrero, J. M. Briceño. "La identidad europea en una visión latinoamericana". In: Bernd, Zilá (org.). Olhares cruzados. Porto Alegre: Editora da Universidade / UFRGS, 2000. 11-17

Hall, Stuart. A identidade cultural na pós-modernidade. Rio de Janeiro: DP \& A Editora, 1999.

Hanciau, Nubia Jacques, Eliane T. A. Campello and Eloína Prati dos Santos (org.). A voz da crítica canadense no feminino. Rio Grande: Editora da FURG, 2001.

Harel, Simon (dir.) L'étranger dans tous ses états: enjeux culturels et littéraires. Montréal: XYZ, 1992. 
Hassoun, Jacques. L'exil de la langue: fragments de langue maternelle. Paris: Point Hors Ligne, 1993.

Jonassaint, Jean. Le pouvoir des mots, les maux du pouvoir: des romanciers haitiens de l'exil. Paris: Éditions de l'Arcantère; Montréal: Préambule, 1989.

Kristeva, Julia. "En deuil d'une langue". In: Czechowki, Nicole and Claudie Danziger (org.). Deuils: vivre, c'est perdre. Paris: Éditions Autrement, 1992.

Kwaterko, Józef. "Ya-t-il un texte migrant dans la classe? L'enseignement et l'intégration culturelle des immigrants au Québec".In: Quebec Studies: Focus on Cultural

Pluralism in Quebec. The American Council for Quebec studies, 1992. 1-6

Lamore, Jean. "Transculturation: naissance d'un mot". In: Lacroix, Jean-Michel and Fulvio Caccia. Métamorphoses d'une utopie. Paris: Presses de la SorbonneNouvelle; Montréal: Éditions Tryptique, 1992. 43-48

Lesser, Jeffrey. A negociação da identidade nacional: imigrantes, minorias e a luta pela etnicidade no Brasil. São Paulo: UNESP, 2001.

Laroche, Maximilien. La double scène de la représentation: oraliture et littérature dans la Caraibe. Québec: Université Laval, 1991.

Larue, Monique. L'arpenteur et le navigateur. Montréal: Fides/CÉTUQ, 1996.

Lequin, Lucie. "L'épreuve de l'exil et la traversée des frontières. Des voix de femmes". Québec Studies, n 14 The American Council for Quebec Studies. 1992. 31-45

Maalouf, Amin. Les identités meurtrières. Paris: Bernard Grasset, 1998.

Micone, Marco. "L'appropriation culturelle comme partage". In: Dionne, Claude et alii. Recyclages: économies de l'appropriation culturelle. Montréal: Les Éditions Balzac, 1996.

Nepveu, Pierre L'écologie du réel: mort et naissance de la littérature québécoise contemporaine. Montréal: Boréal, 1988. 15-31

"Qu'est-ce que la transculture?" Paragraphes 2 . Autrement le Québec: conférences 1988-1989 n². Montréal: Université de Montréal, 1989. 
and Giles Marcotte (dir.). Montréal imaginaire. Ville et littérature. Montréal: Fides, 1992.

Noël, Francine. Nous avons tous découvert l'Amérique. Montréal: Leméac / Actes Sud, 1992.

Ollivier, Émile. Passages. Montréal: Hexagone, 1991.

Palmier, Jean-Michel. Weimar en exil. L'exil en Europe. Paris: Payot, 1988.

Porto, Maria Bernadette. Fronteiras, passagens, paisagens na literatura canadense. Niterói: EDUFF/ABECAN, 2000.

. "Mutações e (i)migrações no espaço quebequense". In: Porto, Maria Bernadette.

Fronteiras, passagens, paisagens na literatura canadense. Niterói: EDUFF/ABECAN, 2000.

Robin, Régine.. "Les champs littéraires sont-ils désespérément monolingues? Les écritures migrantes". In: Gravili, Anne de Vaucher (org.) D'autres rêves: les écritures migrantes au Québec. Actes du Séminaire international du CISQ à Venise (15-16 octobre 1999). Veneza: Supernova, 2000. 19-43

"Défaire les identités fétiches". In: Létourneau, Jocelyn (dir.). La question identitaire au Canada francophone: récits, parcours, enjeux, hors-lieux. SainteFoy, Les Presses de l'Université Laval, 1994. 215-240

Le deuil de l'origine: une langue en trop, une langue en moins. Presses Universitaires de Vincennes, 1993b.

__ Le Golem de l'écriture: de l'autofiction au Cybersoi. Montréal: XYZ, 1997.

L'immense fatigue des pierres. Montréal: XYZ, 1996.

"À propos de la notion kafkaïnne de littérature mineure. Quelques questions posées à la littérature québécoise". In: Paragraphes 2. Autrement le Québec: conférences 1988-1089. Montréal: Université de Montréal, 1989. 5-14

La Québécoite. Montréal: Typo, 1993a. 
106 Maria Bernadette Velloso Porto

"Sortir de l'ethnicité". In: Lacroix, Jean-Michel and Fulvio Caccia. Métamorphoses d'une utopie. Paris: Presses de la Sorbonne Nouvelle; Éditions Tryptique, 1992. $25-41$

Sibony, Daniel. Entre-deux: l'origine en partage. Paris: Seuil, 1991.

Torres, Sonia. Nosotros in USA: literatura, etnografia e geografias de resistência. Rio de Janeiro: Zahar, 2001. 